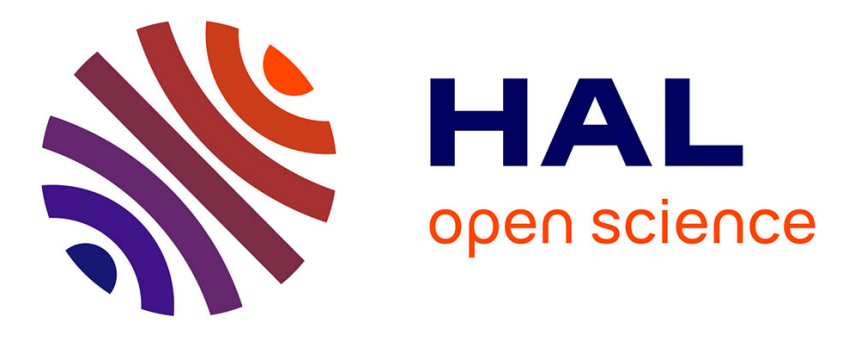

\title{
Bulk and surface core level binding energies in the Pt80Fe20(111) alloy
}

Nicholas Barrett, Claude Guillot, Jean-Claude Bertolini, Jean Massardier, Badal Khanra

\section{- To cite this version:}

Nicholas Barrett, Claude Guillot, Jean-Claude Bertolini, Jean Massardier, Badal Khanra. Bulk and surface core level binding energies in the Pt80Fe20(111) alloy. Surface Science Letters, 1992, 260, pp.L11-L16. 10.1016/0039-6028(92)90008-T . hal-00006216

\section{HAL Id: hal-00006216 https://hal.science/hal-00006216}

Submitted on 8 Nov 2021

HAL is a multi-disciplinary open access archive for the deposit and dissemination of scientific research documents, whether they are published or not. The documents may come from teaching and research institutions in France or abroad, or from public or private research centers.
L'archive ouverte pluridisciplinaire HAL, est destinée au dépôt et à la diffusion de documents scientifiques de niveau recherche, publiés ou non, émanant des établissements d'enseignement et de recherche français ou étrangers, des laboratoires publics ou privés.

\section{(c)(1)}

Distributed under a Creative Commons Attribution| 4.0 International License 


\title{
Bulk and surface core level binding energies in the $\mathrm{Pt}_{80} \mathrm{Fe}_{20}(111)$ alloy
}

\author{
N. Barrett, C. Guillot \\ Laboratoire LURE, Centre Universitaire Paris Sud, 91405 Orsay Cedex, France \\ and \\ DRECAM-SRSIM CE, Saclay, 91191 Gif-sur-Yvette Cedex, France
}

J.C. Bertolini, J. Massardier

Institut de Recherches sur la Catalyse, 2 avenue Albert Einstein, 69626 Villeurbanne Cedex, France

and

B.C. Khanra

Saha Institute of Nuclear Physics, Sector 1, Block AF, Bidhannagar, Calcutta, 700064, India

Core level photoemission spectroscopy of the $\mathrm{Pt} 4 \mathrm{f}_{7 / 2}$ level is used to investigate the surface and bulk Pt environments in the ordered catalytic alloy $\mathrm{Pt}_{80} \mathrm{Fe}_{20}$. The results obtained support a LEED model of $\mathrm{Pt}$ segregation to the surface. This implies the presence of two Pt surface sites.

\section{Introduction}

Single crystal alloys are used as model catalysts in order to get a very good definition of the local order at the surface, i.e., a perfect knowledge of the structure and the external composition making possible the determination of the active surface sites for catalysis. It has been previously demonstrated that the performances of $\mathrm{Pt}_{80} \mathrm{Fe}_{20}$ (111) single crystal alloys for the hydrogenation of both $\alpha-, \beta$-ethylenic aldehydes [1] and 1,3butadiene [2] are considerably better than those of pure Pt(111) despite the fact that the surface layer was pure platinum. Indeed, a quantitative LEED study [3] has shown that the first layer is nearly pure $\mathrm{Pt}\left(\mathrm{C}_{1} \approx 100\right.$ at $\left.\%\right)$. The composition of underlayers, $80 \pm 5$ at $\%$, approaches rapidly the nominal bulk composition. Moreover, the bulk alloy exhibits the $\mathrm{Pt}_{3} \mathrm{Fe}$ ordered $\mathrm{L} 12$ structure type $\left(\gamma_{3}\right.$ phase) which extends up to the subsur- face layer. This leads to a $(2 \times 2)$ LEED structure in which one quarter of the surface $\mathrm{Pt}$ atoms is located slightly out of the surface plane and are bonded to three $\mathrm{Pt}$ atoms in the sublayer whilst three quarters of the atoms has two Pt and one $\mathrm{Fe}$ atoms as first nearest neighbours in the subsurface layer [3].

The repetition of (111) planes in the bulk alloy following the stoichiometry is represented schematically in fig. 1 . The termination of the bulk alloy by a surface layer of pure $\mathrm{Pt}$ as described above is illustrated in fig. 1b. The substitution of a Pt for a Fe leads to an additional Pt surface site, here labelled $S^{\prime}$. This will be important for the interpretation of the photoemission results.

In addition to this specific surface arrangement attention must be focused on the comparison between the electronic properties of the $\mathrm{Pt}$ monolayer in the PtFe alloy and this one for $\mathrm{Pt}$ 

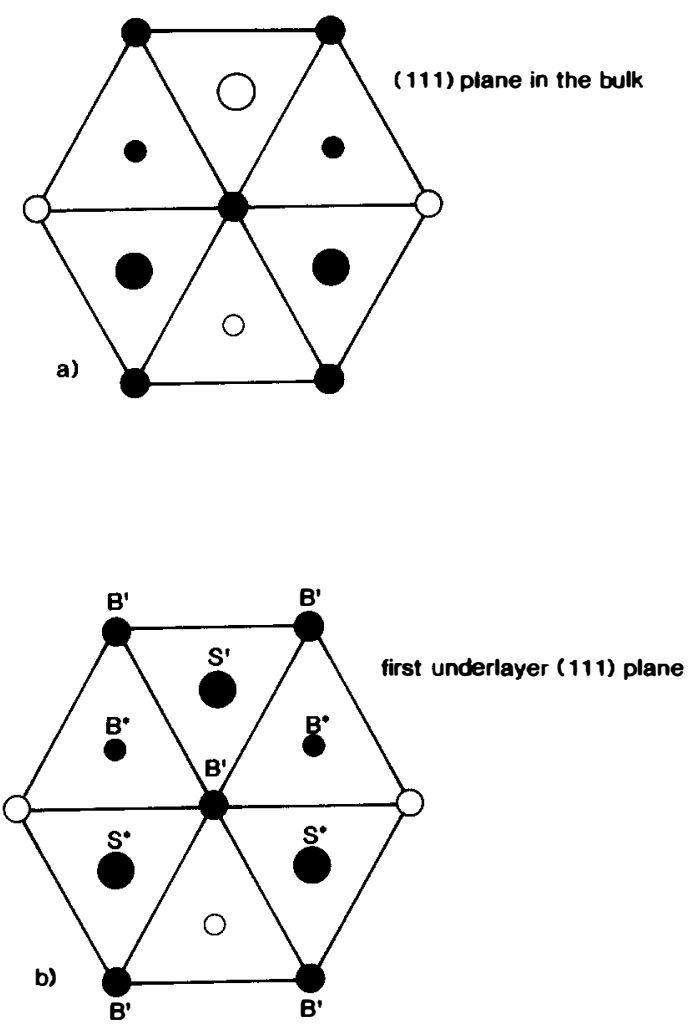

Pt

$\bigcirc \mathrm{Fe}$

larger atoms are in the adjacent plane above.

smaller atoms are in the plane bolow.

Fig. 1. (a) Top schematic view of a (111) phase in the bulk $\mathrm{Pt}_{80} \mathrm{Fe}_{20}$. (b) Top view of the (111) surface in $\mathrm{Pt}_{80} \mathrm{Fe}_{20}$ showing the surface, 1 st and 2 nd underlayers. The different $\mathrm{Pt}$ environments identified in the photoemission spectra are indicated.

monolayer in pure Pt. X-ray photoemission core level spectroscopy is a powerful tool. From the measurement of the core level binding energy, and comparison with calculated binding energies based on an electronic model, we can make inferences about the electronic structure and thus about the catalytic properties of the alloy surface. In general core level spectroscopy is not sensitive enough to surface atoms, and one obtains information on the bulk electronic structure. However the use of high resolution photoemission spectroscopy with tunable synchrotron radiation has made it possible to distinguish between surface and bulk atoms, and to measure their respective core level shifts $[4,5]$.

The present work is devoted to the determination of the bulk and of the surface $4 f_{7 / 2}$ core level binding energies of $\mathrm{Pt}$ in a $\mathrm{Pt}_{80} \mathrm{Fe}_{20}(111)$ alloy. In the next section the experiments will be described. The results, discussion and analysis are presented in section 3 .

\section{Experimental}

The $\mathrm{Pt}_{80} \mathrm{Fe}_{20}$ single crystal was grown using the Czochralski method. The nominal composition is 80.4 at\% $\mathrm{Pt}$ as controlled by atomic absorption spectroscopy. By X-ray emission under scanning electron microscopy it has been verified that the composition is very uniform within 1 at $\%$ along the sample. The sample was spark cut in the form of a thin disk along the (111) orientation, and then polished down up to $1 \mu \mathrm{m}$. It was checked that the (111) plane was parallel to the polished surface within less than $0.1^{\circ}$. Once in vacuum the surface was recrystallized up to the very surface by repeated heatings at about 1350 $K$. The clean surface was obtained by repeated cycles of argon ion bombardments and annealings at about $1200 \mathrm{~K}$ until no impurities were detectable as checked by Auger spectrometry. The surface exhibits then a characteristic $(2 \times 2)$ LEED pattern with supplementary spots having low intensities [3].

The $\mathrm{Pt}_{x} \mathrm{Fe}_{1-x}$ phase diagram shows a transition from the ordered arrangement to the solid solution near $1500 \mathrm{~K}$ for $x=0.8[6,7]$. It has been checked that the ordered phase remains even after the treatments at the highest annealing temperature used $(1350 \mathrm{~K})$, both for the bulk and surface $\mathrm{p}(2 \times 2)$ structure.

The photoemission experiments were performed on the line SA73 of the Super ACO storage ring, LURE, Orsay. A TGM $15^{\circ}$ was used, giving a overall resolution (slits, monochromator and electron analyser combined), of 200$250 \mathrm{meV}$. We have used the tunability of synchrotron radiation to vary the incident photon energy, and hence the kinetic energy of the pho- 
toelectrons. The energy dependence of the electron mean free path thus allows us to vary the sampling depth and consequently to distinguish surface from bulk contributions. Different surface treatments were also used to isolate bulk emission from surface emission: $\mathrm{CO}$ adsorption, carbide formation.

\section{Results and discussion}

Core level shifts are normally measured with respect to a known reference: the position of the core level emission from the pure bulk material. In the case of an alloy the situation is clearly more complicated and requires a precise determination of the bulk (and surface) alloy peak(s) in the ordered or disordered states before interpreting the effect of segregation. By a variety of surface treatments we have bulk peaks, these procedures will now be described in detail. Two treatments were employed: (a) exposure of the surface to $\mathrm{CO},(\mathrm{b})$ reaction of the surface with $\mathrm{C}$ migrating from the bulk to form a surface carbide.

All spectra have been normalised to the continuous background and a linear background function was subtracted. In each case the $\mathrm{Pt} 4 \mathrm{f}_{7 / 2}$ spectra were compared to the clean surface. These spectra were recorded for an incident photon energy of $130 \mathrm{eV}$, roughly corresponding to the minimum in the photoelectron mean free path, thus optimising the surface sensitivity. All the spectra are of course calibrated with the $E_{\mathrm{F}}$ for each spectrum. They are shown in fig. 2 .

If we subtract from the clean surface the spectra corresponding to the $\mathrm{CO}$ exposed sample (treatment a) and to the carbide surface (treatment b) we expect that the surface contributions for these spectra are completely extinguished since Auger measurements show that the $\mathrm{CO}$ and $\mathrm{C}$ coverages correspond respectively to about 1 ML and more than $1 \mathrm{ML}$. The shift of the peaks to higher binding energies and the attenuation of the integrated intensity are both in agreement with the lack of surface contributions in spectra a and $b$.

The difference spectra between the clean surface and the surfaces having undergone the treatments $a$ and $b$ give the components of the $4 f_{7 / 2}$ which are due to the surface treatment. This surface component is then subtracted from the original data to yield the bulk contribution of the clean alloy. The following results are obtained: Clean surface minus treatment a:

$$
\begin{array}{lr}
\text { Position max (eV) } & 71.1 \\
\text { FWHM (eV) } & 1.0
\end{array}
$$

Clean surface minus treatment b:

$$
\text { Position max (eV) } 71.2
$$$$
\text { FWHM (eV) } 0.8 \text {. }
$$
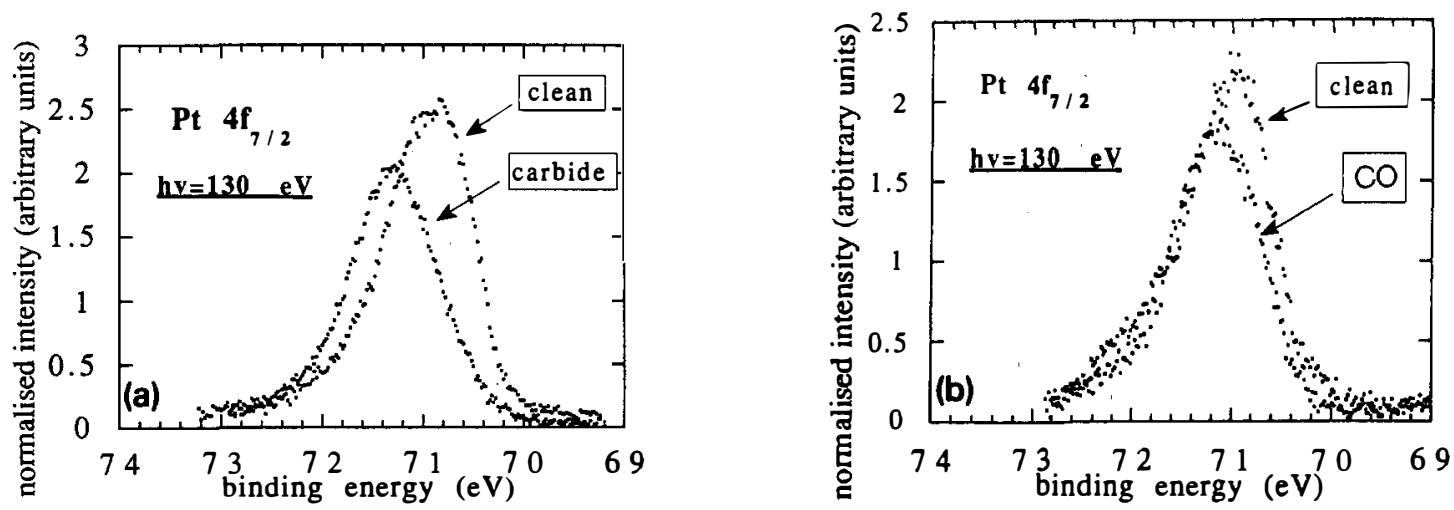

Fig. 2. (a) Background subtracted, normalised data comparing the $\mathrm{Pt} 4 \mathrm{f}_{7 / 2}$ spectra for the clean and carbide alloy surfaces. (b) Same comparison between clean and $\mathrm{CO}$ adsorbed surface. 

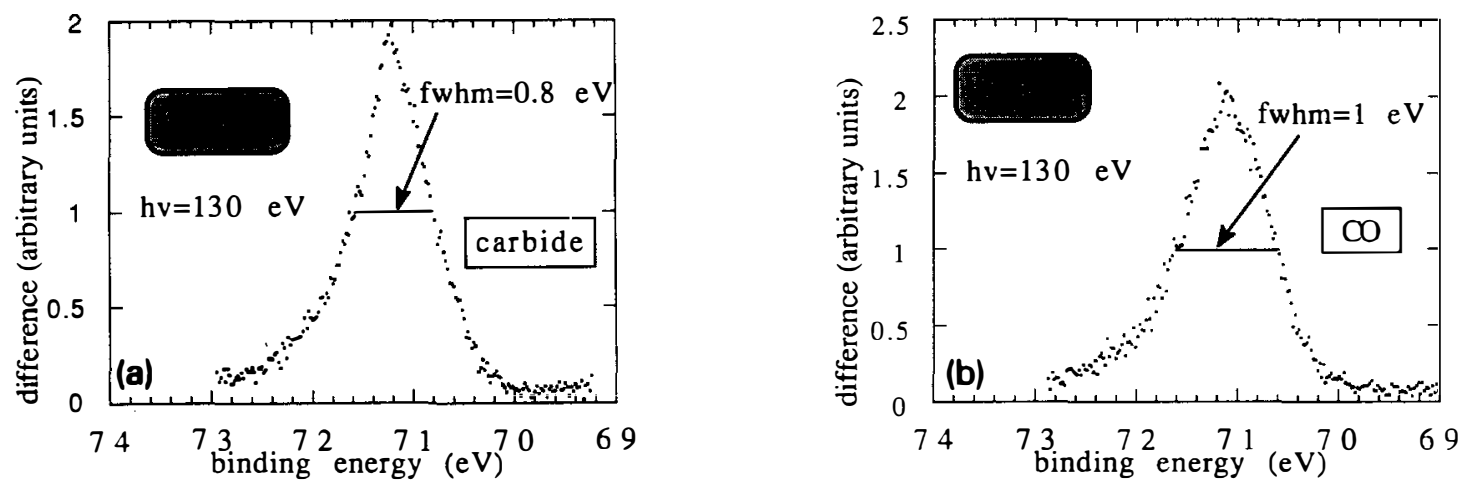

Fig. 3. Determination of bulk contribution obtained by resubstracting the difference spectra of fig. 2 from the original spectra for the clean alloy surface.

These values should be compared to the bulk $B_{0}$ and surface $S_{0}$ binding energies for Pt(111), typically 71.1 and $70.7 \mathrm{eV}$, respectively $[8,9]$.

The results are shown in fig. 3 . Note that the slightly unrealistic sharpness of the peaks results from taking difference spectra which automatically fail to account for overlapping tails. Literature values for $P t 4 f_{7 / 2}$ lineshape parameters suggest a FWHM including the experimental resolution of 0.75 to $0.8 \mathrm{eV}$. We conclude that the difference spectrum between the clean surface and the treatment $b$ corresponds to the main bulk peak and that the difference spectrum obtained after the treatment a in fact represents two peaks, one at $71.2 \mathrm{eV}$ and the second at a lower binding energy. This may be understood by considering the nature of a carbide compared to the $\mathrm{CO}$ saturated surface. The carbon originates from the bulk and is therefore more probably in the surface region. Thus both surface and first underlayer may be involved in metal carbon bonding. $\mathrm{CO}$, on the other hand, sits on top of surface and therefore can interact only with the surface plane atoms. For a determination of the position of the
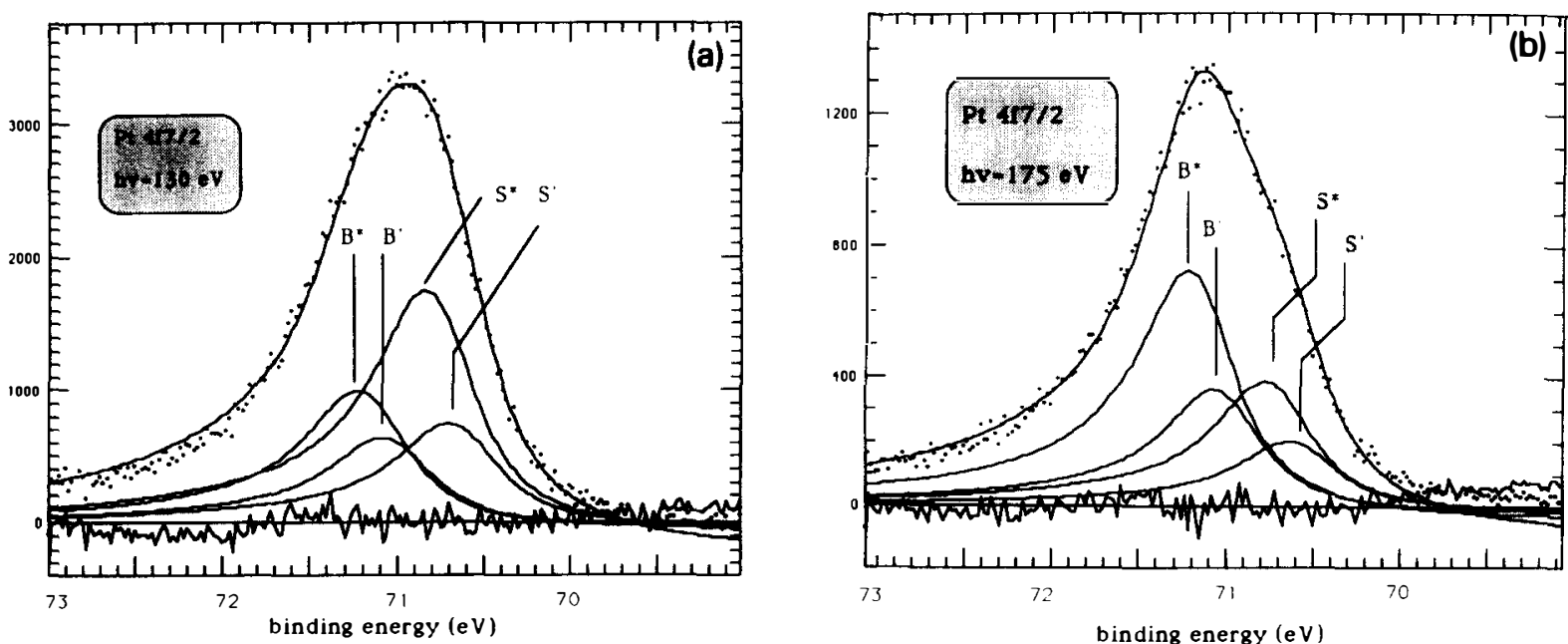

Fig. 4. (a) Decomposition of the $\mathrm{Pt} 4 \mathrm{f}_{7 / 2}$ spectrum for $h \nu=130 \mathrm{eV}$ showing clearly how the surface emission is favoured with respect to the bulk. (b) Same spectrum for $h \nu=175 \mathrm{eV}$ weighting the emission in favour of the bulk atoms. 
bulk peak we use the result of fig. $3 \mathrm{~b}$. A second bulk-like site has to be taken into consideration to explain the widening of fig. $3 a$.

Having determined the bulk and surface peak positions in the ordered state we may use this information to deconvolve the spectra recorded on the segregated alloy. The lineshape parameters are known (Doniach-Sunjic, $2 \gamma=0.5$, alpha $=0.19$ ), the two peak positions are fixed (71.2 and $70.7 \mathrm{eV}$ ), leaving only the respective amplitudes variable.

The spectra were recorded for a series of incident photon energies ( $h \nu=110$ to $200 \mathrm{eV}$ ) in order to favour one or other of the surface and bulk emissions. In order to fit the data it is necessary to include two additional peaks, $\mathbf{B}^{\prime}$ and $S^{\prime}$, shifted to lower binding energies by $140 \mathrm{meV}$ with respect to the main contributions $\mathrm{B}^{*}$ and $S^{*}$. The same lineshape parameters are of course used. Two such decompositions are shown in fig. 4 for photon energies of 130 and $175 \mathrm{eV}$. We can clearly see how, by tuning the synchrotron radiation, the surface sensitivity may be increased with respect to the bulk or vice versa. The results are shown in fig. 5 which traces the variation of each peak intensity as a function of incident photon energy.

There is clearly a relationship between the different electronic states observed in core level photoemission and the geometry of the system (fig. 1). At the surface we can distinguish two sites: the majority of $\mathrm{Pt}$ atoms (in the all $\mathrm{Pt}$ surface layer) have $2 \mathrm{Pt}$ and $1 \mathrm{Fe}$ neighbour in

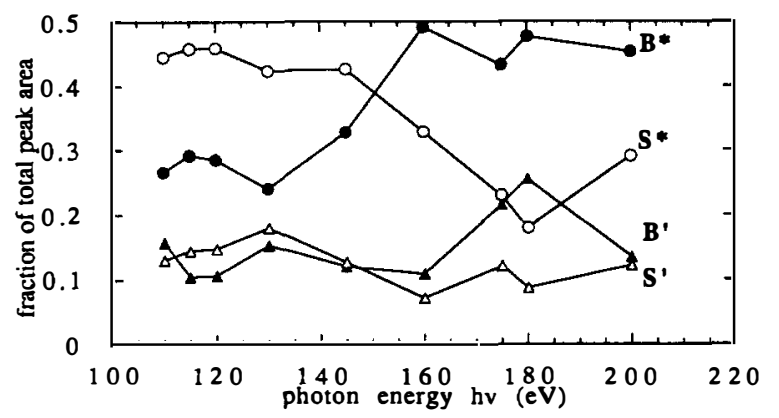

Fig. 5. Evolution of the peak areas $B^{*}, B^{\prime}, S^{*}$ and $S^{\prime}$ as a function of incident photon energy. The surface sensitivity of the technique is revealed by the energy dependence of $V^{*}$ ad $\mathrm{S}^{*}$. There is also some evidence for diffraction effects. the first underlayer and we represent this by $\mathrm{S}$ * $\left(E_{\mathrm{B}}=70.76 \mathrm{eV}\right)$; a minority of $\mathrm{Pt}$ atoms have $3 \mathrm{Pt}$ neighbours in the first underlayer, this site is called $S^{\prime}\left(E_{\mathrm{B}}=70.62 \mathrm{eV}\right)$.

The bulk Pt $\mathrm{B}^{*}$ has a binding energy of 71.2 $\mathrm{eV}$. There is a further contribution $\mathrm{B}^{\prime}$ at a binding energy of $71.06 \mathrm{eV}$, which probably corresponds, in the model presented in fig. 1, to the first underlayer $\mathrm{Pt}$ atoms which, because of the $\mathrm{Pt}$ surface segregation have a $\mathrm{Pt}$ rich environment with respect to the bulk. However, we cannot a priori exclude the possibility that this peak $B^{\prime}$ is due to bulk Pt atoms in Pt aggregates, which form in order to compensate for the difference between the stoichiometry of $\mathrm{Pt}_{3} \mathrm{Fe}$ and $\mathrm{Pt}_{80} \mathrm{Fe}_{20}$. The first assumption is further supported by the determination of $B^{*}$ from the surface treatment $\mathrm{b}$, indicating the existence of a single bulk peak. Furthermore, if $\mathbf{B}^{\prime}$ were assigned to Pt clusters in the bulk we would have to assume these to be below the second surface layer. Given the surface sensitivity of photoemission (for the photoelectron kinetic energies used this would correspond to an attenuation of at least $50 \%$ ), and the small discrepancy in the stoichiometry with respect to $\mathrm{Pt}_{3} \mathrm{Fe}$, we would expect a $\mathrm{B}^{*} / \mathrm{B}^{\prime}$ ratios much larger than those obtained from fig. 5. Thus we conclude in favour of the presence of a second bulk-like site in the sublayer.

We can conclude that the presence of $\mathrm{Fe}$ neighbours shifts the $\mathrm{Pt}_{4 / 2}$ binding energy towards higher binding energies. With respect to the pure metal the $\mathrm{Pt}_{7 / 2}$ in the alloy is only slightly displaced. In addition, the core level energy of the $\mathrm{Fe} 3 \mathrm{p}$ has been measured. The peak feature is asymmetric. Its mean position is 51.4 $\mathrm{eV}$. It corresponds to a shift downwards of more than $1 \mathrm{eV}$, if one refers to values given for pure $\mathrm{Fe}$ [10]. It is obvious that such a shift is associated with an alloying effect in the bulk of the material since no iron is present in the first layer. The asymmetry of the peak could be simply attributed to the $3 p_{1 / 2}$ and $3 p_{3 / 2}$ spin-orbit splitting, with the expected contribution to the peak of respectively $\frac{1}{2}$.

The bulk chemical shift induced by alloying can be calculated using relations which correlate the XPS binding energy shift to solution energies 
in metals [11], based on a Born-Haber thermodynamic cycle which was proposed originally for the pure metals by Martensson and Johansson [12]. For an $A_{x} B_{1-x}$ alloy, the XPS core level chemical shifts for $\mathrm{A}$ and $\mathrm{B}$ elements are expressed as follows:

$$
\begin{aligned}
E^{\mathrm{A}}(x)= & (1-x)^{2}\{E(\mathrm{~A}, \mathrm{~B})+2 x[E(\mathrm{~B}, \mathrm{~A}) \\
& -E(\mathrm{~A}, \mathrm{~B})]\}-(1-x)[E(\mathrm{~A}+1, \mathrm{~B}) \\
& -E(\mathrm{~A}+1, \mathrm{~A})]-x(1-x) \epsilon_{\mathrm{A}+1}, \\
E^{\mathrm{B}}(x)= & x^{2}\{E(\mathrm{~B}, \mathrm{~A})+2(1-x)[E(\mathrm{~A}, \mathrm{~B}) \\
& -E(\mathrm{~B}, \mathrm{~A})]\}-x[E(\mathrm{~B}+1, \mathrm{~A}) \\
& -E(\mathrm{~B}+1, \mathrm{~B})]-x(1-x) \epsilon_{\mathrm{B}+1}
\end{aligned}
$$

Where $E(X, Y)$ represents the partial solution energy for $X$ into $Y$ and $\epsilon_{\mathrm{A}+1}$ and $\epsilon_{\mathrm{B}+1}$ a first order correction parameter to the non-linearity of the dependence of the solution energy for $A+1$ and for $\mathrm{B}+1$ in $\mathrm{A}_{x} \mathrm{~B}_{y}$ alloy. In the present case $\mathrm{A}=\mathrm{Pt}, \mathrm{A}+1=\mathrm{Au}, \mathrm{B}=\mathrm{Fe}, \mathrm{B}+1=\mathrm{Co}$.

Neglecting the first order correction to the non linearity of the dependence of the solution energy $\epsilon_{\mathrm{A}+1}$ for $\mathrm{Au}$ in $\mathrm{Pt}_{80} \mathrm{Fe}_{20}$, and using the solution energy values given by Miedema et al. [13] - i.e., $E(\mathrm{Pt}, \mathrm{Fe})=0.6 ; \quad E(\mathrm{Fe}, \mathrm{Pt})=0.5 ; \quad E(\mathrm{Au}, \mathrm{Fe})=$ $-0.4 ; E(\mathrm{Au}, \mathrm{Pt})=-0.2 ; \quad E(\mathrm{Au}, \mathrm{Fe})=-0.4$; $E(\mathrm{Co}, \mathrm{Pt})=0.26$ and $E(\mathrm{Co}, \mathrm{Fe}) \approx 0 \mathrm{eV} /$ atom $-\mathrm{a}$ XPS core level shift of $+0.06 \mathrm{eV}$ is expected for the $\mathrm{Pt} 4 \mathrm{f}$ level in the $\mathrm{Pt}_{80} \mathrm{Fe}_{20}$ alloy. This value is in quite good agreement with the experimental determination, $+0.1 \mathrm{eV}$ according to the values given in refs. [8] and [9] for pure Pt. Such a calculation is even more complex for the surface $\mathrm{Ft}$ atoms, as much as two $\mathrm{Pt}$ surface sites are present in the $\mathrm{Pt}_{80} \mathrm{Fe}_{20}(111)$ alloy. Using the same approach for $\mathrm{Fe}$, a near zero shift is expected. Consequently, the term related to the deviation with respect to the non linearity of the solution energy of Co in $\mathrm{Pt}_{80} \mathrm{Fe}_{20}$ plays, say $\epsilon_{\mathrm{B}+1}$, a major role, and has to be taken into account in the calculation.

In conclusion, among the surface Pt atoms, which are the active sites, some are influenced by the neighbouring of $\mathrm{Fe}$ atoms. While the core level shift is rather small, important effects are observed for the catalytic properties of such an alloy $[1,2]$. That would reflect modifications of the electronic structure in the valence band, such as changes of the hybridization of some Pt surface sites. Calculations are underway to model this.

\section{References}

[1] P. Beccat, J.C. Bertolini, Y. Gauthier, J. Massardier and P. Ruiz, J. Catal. 126 (1990) 451.

[2] J.C. Bertolini and J. Massardier, Catal. Lett. 9 (1991) 183.

[3] P. Beccat, Y. Gauthier, R. Baudoing-Savois and J.C. Bertolini, Surf. Sci. 238 (1990) 105.

[4] Y. Jugnet, G. Grenet and Tran Minh Duc, Hand book of Synchrotron Radiation, Vol. 2, Ed. G.V. Marr (Elsevier, Amsterdam, 1987) p. 663.

[5] D. Spanjaard, C. Guillot, M.C. Desjonquères, G. Tréglia and J. Lecante, Surf. Sci. Rep. 5 (1985) 1.

[6] W.G. Moffatt, The handbook of binary phase diagrams, Genium Publishing Corporation, 1990).

[7] R. Hultgren et al., Selected values of the thermodynamic properties of binary alloys, American Society for Metals, 1973.

[8] P. Légaré, G. Lindauer, L. Hilaire, G. Maire, J.J. Ehrhardt, J. Jupille, A. Cassuto, C. Guillot and J. Lecante, Surf. Sci. 198 (1988) 69.

[9] C. Boeglin, A. Barbier, F. Scheuer, B. Carrière and J.P. Deville, J. Magn. Magn. Mater. 93 (1991) 31.

[10] B. Egert and G. Panzner, Surf. Sci. 118 (1982) 345, and references there in.

[11] P. Steiner and S. Hufner, Acta Metall. 29 (1981) 1885.

[12] N. Martensson and B. Johansson, Solid State Commun. 32 (1979) 791 ;

B. Johansson and N. Martensson, Phys. Rev. B 21 (1980) 4427.

[13] A.R. Miedema, P. F de Chatel and F.R. de Boer, Physica B 100 (1980) 1. 